given for the procedures advocated. In reading one section of the book, the student is continually referred back to some otber page, and as there are no less than 830 pages, these references back become exasperating.

Some of the language seems to us a little unfortunate. In talking of ventilation of the sick room, is "foul air" a really good description? What is "an anastomising operation"? We rather object to the term "purifying the abdomen before operation". A patient surely has every right to consider her abdomen as pure as the light of day, even though it be necessary to render it as aseptic as possible prior to a laparotomy.

We also question one or two statements in this book. Is it true, for example, that blood present in all specimens of a test meal necessarily indicates a large ulcer or carcinoma? In speaking of Lyons' method of drainage of the gall-bladder, the authoress seems to confuse both Einhorn and Ryle's tube with a stomach tube. We also think that there are not many hands that will stand 1 in 40 carbolic. We are sorry that the authoress still uses the term "fæcal vomit". Most authorities agree that fæcal vomiting does not occur, and that the vomit is really intestinal. The authoress, moreover, goes so far as to say that solid fæcal matter may be vomited; this we have never seen in a pure case of intestinal obstruction. We do not like the administration of calomel as a post-operative aperient, and although it is stated that it may be followed by a dose of sulphate of magnesia, the "may" should read "must". In discussing tourniquets, we are surprised that the authoress does not even mention Martin's bandage. Nowadays this should generally be used in preference to the ordinary Esmarch's tourniquet, so beloved of first-aid and Government circles. In cleaning tracheotomy tubes, feathers are still recommended. This is an example of aged practice which should be superseded, as it is difficult, if not impossible. to sterilize a feather, and they are not always to be obtained, especially in these days. A small pledget of sterilized wool or gauze is much more satisfactory for the purpose.

In a work of this size it is perhaps inevitable that inaccuracies should creep in. On the other hand, in dealing with nurses, one has to be particularly careful from the point of view of descriptive language. As a teacher and examiner of nurses for many years, the reviewer is only too well aware of how words and expressions are used by nurses as a cloak for ignorance, and loose phraseology is apt to be misunderstood and to create an impression the reverse of what is intended.

There are many things in this book which are well described and the illustrations are excellent, but in our view the work suffers from its merits. That is, an attempt has been made to compress into a reasonable space something like an encyclopædia-an impossible task. This probably accounts for the short, disjointed sentences and the references back referred to above, which make the book difficult to read and to hold the attention. On the other hand, if this book is meant purely for reference purposes, it is of great value.

\section{HUMAN HISTOLOGY}

\section{A Guide for Medical Students.}

By E. R. A. Cooper, M.D., M.Sc., Lecturer in Histology, University of Manchester. Pp. xiv +424 with 237 illustrations. Price 16s. 0d.

Dr. Cooper has succeeded in producing an ideal book for the medical student who, with the limited time at his disposal, wishes to acquire a sound knowledge of histology.

Obviously great care has been taken in the choice and preparation of the numerous photomicrographs to include only such specimens as the student will himself see under the microscope.

The author's style is both lucid and concise and this coupled with the excellent illustrations, whose value is enhanced by very clear labelling, renders this a most readable text book.

\section{WAR-WOUNDS AND AIR RAID CASUALTIES.}

(Articles reproduced from The British Medical Journal.) H. K. Lewis \& Co. Ltd. 1939. Price 10s. 6d.

War Wounds and Air Raid Casualties by Various Authors consists of articles republished from The British Medical Journal, and bears the impress of haste and carelessness in the coordination of the teaching by different contributors. In an excellent article by Major A. Tudor Hart on "War Surgery in Spain," which gives independent testimony to the value of the principles advocated by Trueta, there occurs the clear-cut injunction that "Amputation is not indicated except in cases of massive gangrene" (p. 63), whereas in the article by Mr. Philip Mitchener (p. 111) occurs the equally dogmatic counsel that " In cases in which gas gangrene manifests itself prompt amputation will offer the best chance of saving the patient's life."

The twenty-three articles give one the impression of having met casually at the club and agreed to give a variety performance for the instruction of those young surgeons who may be called upon to handle prospective casualties.

The standard attained in many of the articles is very high. Nothing could surpass the clarity of statement and convincing teaching of $\mathrm{Mr}$. Jefferson's "War Wounds of the Head," nor the grace of diction and fearless common sense of Mr. Gordon-Taylor's "Abdominal Injuries."

It should come as a relief to students that $\mathrm{Mr}$. Max Page in a refreshingly candid article "Amputations under War Conditions," counsels the adoption of the amputations advised by the Ministry in a recent publication, wherein the demands of the instrument-maker are set forth.

The authority of his great experience confirms the need to abandon demanding from students a knowledge of some of the old, now discredited, amputations such as the Stokes-Gritti. 